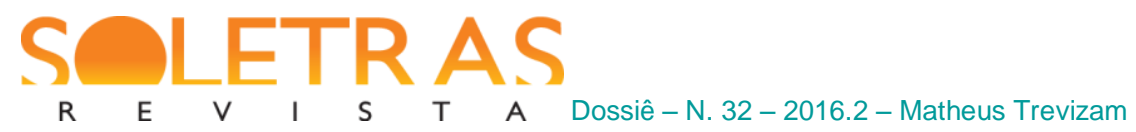

\title{
Paralelos entre o Cynegeticon e o livro III das Geórgicas de Virgílio*1
}

\author{
Matheus Trevizam² \\ Universidade Federal de Minas Gerais
}

Resumo: Neste artigo, intentamos o cotejo, em partes especificas, dos poemas didáticos de Virgílio (Geórgicas, livro III) e Grattius Faliscus (Cynegeticon). Nosso objetivo, através das análises propostas, as quais se referirão, por um lado, a v. III, 72-122/179-208 da primeira obra citada e a v. 497-541 do outro poema (assunto dos cuidados necessários aos equinos) e, por outro, a v. III, 440-456 dessa obra de Virgílio e a v. 408-429 da de Grattius (tratamento da sarna de ovelhas e cães, respectivamente), diz respeito a afinar o entendimento a respeito de como tais textos se aproximam ou afastam, por suas características de tessitura poética. $\mathrm{O}$ referencial teórico a que recorremos, sobretudo, diz respeito à ideia dos gêneros literários, tal como usual nos Estudos Clássicos, e, em particular, à noção de poesia didática antiga, a qual reputamos, com outros estudiosos (TOOHEY, 1996/2004), passível de dividir-se em subtipos. Os resultados obtidos através da comparação de trechos tematicamente afins de Virgílio e Grattius Faliscus, como acima os delimitamos, permitem-nos concluir que em Geórgicas III prevalece um tipo de estruturação textual voltado para o deleite estético e da imaginação do público, enquanto em Cynegeticon o autor se faz, amiúde, maciçamente informativo sobre o assunto da caça.

Palavras-chave: Gênero literário. Poesia didática antiga. Comparação.

\section{Introdução}

\footnotetext{
* Meus agradecimentos à professora Isabella Tardin Cardoso - IEL-Unicamp - pela generosa disponibilização do comentário de Verdière sobre o Cynegeticon de Grattius, tratando-se de obra de acesso difícil no Brasil; meus sinceros agradecimentos também a Roque Tumolo Neto pelo auxílio com o resumo em inglês.

2 Matheus Trevizam, licenciado e bacharel em Letras pela Universidade Estadual de Campinas, além de mestre e doutor pela mesma Instituição, é professor de Língua e Literatura Latina na Faculdade de Letras da UFMG, Belo Horizonte. Realizou estágio pós-doutoral na Universidade de Paris-Sorbonne (França) e atualmente edita o periódico Nuntius Antiquus (FALE-UFMG), especializado em Literaturas antigas e medievais.
} 
Em Cynegeticon, poema de caça atribuído ao obscuro ${ }^{3}$ Grattius Faliscus - época augustana -, e no livro III das Geórgicas, de Virgílio, veem-se textos, até certo ponto, afins. Primeiramente, tais "espécimes" literários são obras atinentes ao que a crítica moderna, em geral, tem chamado de "poesia didática": isso se identifica, grosso modo, com um tipo de produção quase sempre escrita em hexâmetros datílicos ${ }^{4}$, cujo foco emissor da "voz" textual se molda como um magister ("professor"), endereçando-se ele a um público "recortado" como discipulus ("aluno"). Além disso, as obras dessa tipologia devem apresentar intenção instrutiva declarada (amiúde, séria) e contêm, de entremeio, uma série de excursos de natureza narrativa, ou mítica (TOOHEY, 1996, p. 4).

Ainda, não se pode esquecer de que, no universo dos quatro livros "geórgicos", o de número III corresponde àquele mais próximo, tematicamente, do âmbito venatório do poema de Grattius. Na verdade, como o livro I dessa obra de Virgílio aborda o assunto técnico das lavouras, o livro II o da arboricultura e o livro IV a apicultura, é de fato sua terceira parte, cujo tema são as criações de rebanhos de grande e pequeno porte ${ }^{5}$, a que se destaca pela similitude aproximada com um pequeno texto ${ }^{6}$, conforme dissemos, cujos horizontes didáticos de caça permitem a cabível integração de tópicos como os cuidados de cães e cavalos a seus versos.

Se desejássemos direcionar-nos para algumas correspondências mais precisas entre trechos temáticos afins de Geórgicas III e desse Cynegeticon, ser-nos-ia possível dizer que as seções dedicadas aos equinos são, na obra de Virgílio, os versos 72-122/179-2087, enquanto, em Grattius, tem-se para o mesmo tema v. 497-541. Por outro lado, no que diz respeito aos

\footnotetext{
${ }^{3}$ Como dado sumário sobre a "biografia" desse poeta, ocorre, na verdade, que, no verso 40 de sua única obra conservada, o mesmo Grattius empregue a expressão nostris Faliscis ("para os nossos faliscos"), talvez para referir-se aos naturais da cidade itálica de Falerii (na Etrúria) como seus conterrâneos.

${ }^{4}$ A erotodidáxis ovidiana, porém, constituída por obras como a Ars amatoria, os Remedia amoris e os Medicamina faciei femineae, por muitos tidas como representantes da poesia didática antiga (TOOHEY, 1996, p. 157 et seq./ VOLK, 2002, p. 3 et seq.), foi toda composta em dísticos elegíacos, segundo os procedimentos desse poeta de mesclar os gêneros ao escrevê-las (TREVIZAM, 2014, p. 113).

${ }_{5}^{5}$ Até Geórgicas III, 283, Virgílio posiciona-se sobre a criação de cavalos e bovinos; de v. 284 em diante, depois de um segundo proêmio feito para introduzir temas mais humildes, no mesmo livro "geórgico", o autor passa a tratar de ovelhas e caprinos.

${ }^{6}$ No estado fragmentário em que se encontra para nós, modernos, o Cynegeticon de Grattius tem apenas 541 versos. Por outro lado, os sucessivos livros das Geórgicas contam respectivamente com 514, 542, 566 e 566 versos, mas trata-se, é claro, de extensões individuais de um todo construído como um poema didático mais longo, em quatro partes. Sobre a extensão média dos espécimes atinentes à poesia didática antiga, cf. Toohey (1996, p. 4): "Traditionally such poems comprised one book of about 800 lines (but at least 400 lines), although this changed as the form developed".

${ }^{7}$ Entre Geórgicas III, 123-137 - cuidados dos reprodutores e fêmeas antes do cruzamento -, o trecho pode aplicar-se mais ou menos indistintamente, como explica Mynors (VIRGIL, 2003, p. 201), aos dois tipos de animais domésticos "grandes" recobertos pela preceituação nesse livro do poema (bovinos e equinos). Por isso, decidimos não incluí-lo em nossos comentários, para resguardar uma seletividade temática mais clara, em favor apenas dos trechos "geórgicos" ocupados de tecer comentários inequívocos sobre os cavalos.
} 
pontos em que se trata, nessas mesmas duas obras, da espécie dos cães - úteis guardadores de redis nas Geórgicas, além de caçadores, e indispensáveis instrumentos de caça no contexto do Cynegeticon -, deveríamos mencionar, em Virgílio, III, 404-4138 e, em Grattius, v. 150-336.

Como se nota, apesar de os débitos desse poeta ao Virgílio geórgico serem, por vezes, reconhecidos $^{9}$, é inegável que, sob o aspecto da proporcionalidade numérica dos versos destinados, em cada um deles, aos cavalos e cães, tal relação aproximativa não se torna tão óbvia. Com efeito, segundo nosso "recorte", o autor das Geórgicas dispensa em torno de 81 versos à concentrada abordagem da equinocultura, enquanto Grattius, em sua obra notoriamente mutilada ${ }^{10}$, finaliza-a com 45 versos dedicados a esse mesmo tópico de criação animal (podendo-se, talvez, confirmar a hipótese de que fosse expandi-lo bem mais, caso ainda dispuséssemos de seu texto na integralidade) ${ }^{11}$. Ainda, como percebemos ao fazer as contas reveladoras do essencial do "espaço" dedicado por Virgílio e Grattius para os cães nos respectivos Geórgicas III e Cynegeticon, o primeiro poeta destinou meros 10 versos ao tema ${ }^{12}$, enquanto seu "sucessor" na linhagem da poesia didática antiga expandiu-o por nada menos que 187 versos! $!^{13}$

\footnotetext{
${ }^{8}$ Em v. 44, 265, 345, 371, 496 e 540, também há menções pontuais a cachorros no poema didático de Virgílio, mas não se trata de verdadeiras seções em que se exponham, minimamente, os cuidados e empregos desses animais no fundus rusticus.

${ }^{9}$ RODRÍGUEZ, 1984, p. 12: "Aunque ha sido negado, parece claro que han ejercido influencia en Gratio el Cinegético de Jenofonte y, más aún, un desconocido autor alejandrino. De entre los latinos conocía bien a los principales autores de su época, pero sin duda es a Virgilio (y, en particular, a las Geórgicas, como se ha indicado más arriba) a quien más debe: se trata, no obstante, de una lograda asimilación, no de un plagio; el poeta ha sabido recrear, en todo caso, lo que le inspiraban sus modelos, consiguiendo un todo armonioso entre lo griego y lo latino, que llega hasta su concepción filosófica, por lo demás sólo esbozada, equidistante de lo epicúreo y estoico"./ LILLY, 1917, p. 40-41./ Aymard (1938, p. 325), por outro lado, quer atribuir a "inspiração", ou modelo geral desse Cynegeticon, a um tratado alexandrino de caça hoje perdido.

${ }^{10}$ MOYA, 2007, p. 465: "La última parte (502-541), no completa y que va precedida de una breve transición (497-501) sobre la necesidad de tratar también de los caballos relacionados con la cacería, consiste en pasar revista a las distintas razas, acabando con un texto bastante mutilado".

${ }_{11}$ Servindo-nos de um parâmetro de comparação depreensível do próprio Cynegeticon, observamos, por exemplo, que seu autor dividiu a abordagem da espécie canina entre outros pontos, além da menção às raças/tipologia (v. 154-212): seriam eles, depois de um excurso dedicado ao elogio de Hágnon, primeiro a lidar com a raça dos metagontes (v. 213-252), e de um trecho de comentário sobre um tipo canino mesclado com chacais (v. 253-262), pronunciar-se do cruzamento e seleção dos cachorros (v. 263-306), da criação de suas ninhadas (v. 307-327) e das qualidades do tratador de cães e do monteiro (v. 328-336). Assim, não existe motivo para imaginarmos que apenas aos cavalos fosse caber um tipo de abordagem tão mais restritiva quanto aquela agora visível a partir do v. 497 de Cynegeticon...

${ }^{12} \mathrm{O}$ "corte" abrupto de seções vinculadas a assuntos de desenvolvimento poético um pouco mais difícil não é, de modo algum, uma exclusividade desse breve trecho vinculado aos cachorros, nas Geórgicas. Vejam-se, assim, as palavras de Dalzell (1996, p. 107) sobre a facilidade com que o poeta "despede" o tópico sobre as utilíssimas oliveiras em Geórgicas II (por ter preferido, nesse livro "arbóreo", concentrar-se nos comentários sobre as parreiras): "The opening lines of Book 2, which list the principal subjects to be discussed, give the impression that the olive and the vine will be accorded equal treatment. In fact the olive, so important to the Roman economy, is dismissed in six lines (2.420-5)".

${ }^{13}$ Entre v. 344-379, fala-se em Cynegeticon diretamente de doenças que atingem os cães, pelo que preferimos considerar a essa como uma seção à parte do poema, com um prolongamento constituído por v. 480-496 (ritos a
} 
Desse modo, se a existência, nos dois poetas, de razoável quantia de versos que se ocupam de descrever o trato dos equinos parece favorecer a abordagem comparativa de tal assunto em suas obras aqui consideradas, a relativa exiguidade da seção sobre os cães em Geórgicas III já não propicia tanto cotejá-la com a longuíssima parcela correspondente, em Grattius Faliscus (v. 150-336, com interpolações de assuntos marginais em certos pontos). Isso justifica que, depois de cotejar alguns elementos sobre a equinocultura no Virgílio "geórgico" e nesse seu "sucessor", passemos a tratar não de aspectos gerais atinentes aos cães nas Geórgicas e no Cynegeticon, mas, sim, de preceitos veterinários que parecem ter sido "transferidos" das ovelhas virgilianas de III, 440-456 para os cachorros de Grattius, como se mostram em v. 408-429.

\section{O tratamento destinado à espécie equina em Virgílio - Geórgicas III, 72-122/179-208 - e em Grattius Faliscus - Cynegeticon 497-541}

O aspecto inicial que sobressai da comparação entre o tratamento dado aos assuntos de equinocultura no livro III das Geórgicas e no Cynegeticon de Grattius Faliscus diz respeito a que, na primeira obra, a entrada de um tema com semelhantes características é algo artificial, enquanto, no segundo poema, encontra-se justificada. Como ressaltado por alguns estudiosos, entre as "estranhezas" do plano temático das Geórgicas, encontram-se certos efeitos desencadeados pela peculiar "seletividade" de assuntos divisada na obra:

Contudo, a acusação de superficialidade é, ainda assim, justa. Não apenas pontos essenciais são omitidos, mas a seleção é, em si mesma, estranha. O cavalo não era um animal importante nas fazendas itálicas; contudo, dá-se-lhe tratamento épico, enquanto a mula e o burro, de utilidade, são passados em silêncio. ${ }^{14}$

Desse modo, Virgílio preferiu, em um texto com características altamente literárias como as Geórgicas - decerto não destinadas a guia prático de agropecuária para verdadeiros

Diana, rogando sua proteção para tais animais, em caçadas ou contra moléstias). Por outro lado, entre v. 337 343, abordando as vestes do caçador, Grattius a rigor não se pronunciara nem sobre cachorros, nem sobre seus males físicos.

${ }^{14}$ DALZELL, 1996, p. 107: "But the charge of superficiality is none the less fair. Not only are essential points omitted, but the selection is itself strange. The horse was not an important animal on the Italian farm; yet it is given epic treatment, while the useful mule and donkey are passed over". [trad. nossa]

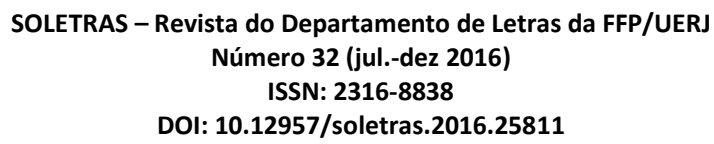


rústicos,$-{ }^{15}$ abordar temas de maior rentabilidade poética, como os próprios equinos, espécie mais "nobre" que simples, mas úteis (ROBERT, 1985, p. 269), burros e, ainda, associável a tantas lendas da mitologia ${ }^{16}$ e ao universo épico. Sobre o aspecto da vinculação dos cavalos à epopeia no livro III das Geórgicas, Leah Kronenberg (2009, p. 151) primeiramente destacou que tais animais se adaptam bem ao tema militar da praelocutio dessa parte do poema, na qual se fala, inclusive, de uma representação de batalha nas portas do templo posto às margens do rio Míncio (v. 26-33); além disso, segundo a mesma estudiosa, em Geórgicas III, “os próprios cavalos são avaliados por seu desejo de glória (102), louvor e vitória (112)""17.

Em contrapartida, o que vemos pela abordagem, embora incompleta, do tratamento dos equinos em Cynegeticon corresponde a algo, como dizíamos, em harmonia com a natureza de uma obra cujo tema central, a caça, vinculou-se mais de uma vez, em contexto antigo, aos auxiliares não humanos identificados não só com os cães (AMAT, 2002, p. 45 et seq.), mas ainda com esses animais de montaria. Na verdade, quando nos referimos a outras obras "cinegéticas" da Literatura greco-latina, sempre se divisam seções dedicadas aos cavalos em textos como os respectivos poemas didáticos de Opiano de Apameia (séc. III d.C.) - Cynegeticon I, 158-367 - e de Nemesiano de Cartago (séc. III d.C.) - Cynegeticon 240-298 -, pois essa espécie obviamente se prestava a favorecer a mais ágil perseguição de presas pelos praticantes do "esporte" aludido ${ }^{18}$.

15 TREVIZAM, 2014, p. 70: "Que dizer, por outro lado, da figura do discipulus nas linhas das Geórgicas? O destinatário nomeado do poema, com esse sentido, é Mecenas, o qual acima apresentamos também como dedicatário da obra e homem forte de Augusto, o primeiro dos imperadores romanos, além de como patrono dos geniais poetas de seu círculo. Do ponto de vista biográfico, referimo-nos aqui a uma personagem com elos familiares na antiga nobreza etrusca, refinada ao extremo em seus gostos materiais e espirituais e, ainda, não desprovida de pretensões literárias. Tal apresentação sumária, esperamos, já deve bastar para fazer vê-lo, em certo sentido, como o oposto do agricola romano a quem, com mais propriedade, voltar-se-iam preceitos afins àqueles constantes das Geórgicas, segundo antes elencados. (...) A nosso ver, o poeta intenta, com semelhantes procederes, dar a entender que se ocupa de um fazer literário, no qual a total seriedade e o comprometimento com oferecer um 'curso de agricultura' resultam secundários diante da opção por favorecer outras camadas significativas da obra".

${ }^{16}$ Para restringir-nos apenas a exemplos hauridos do livro III das Geórgicas, uma imaginativa lenda relatada por Virgílio em v. 266-268 conta que as éguas de Glauco, filho de Sísifo, devoraram-no quando ele as atrelou a um carro de corrida, depois de tê-las privado do sexo para serem mais ardorosas em um páreo (GRIMAL, 1963, p. 166): Scilicet ante omnis furor est insignis equarum/ et mentem Venus ipsa dedit, quo tempore Glauci/ Potniades malis membra absumpsere quadrigae. - "Naturalmente, antes de tudo é admirável o furor das éguas, e a própria Vênus inspirou o sentimento, quando éguas potníades, atreladas em quatro, devoraram os membros de Glauco com suas mandíbulas". [trad. nossa]

${ }^{17}$ KRONENBERG, 2009, p. 163: “(...) the horses themselves are valued for their desire for glory (102), praise, and victory (112)". [trad. nossa]

18 NEMESIANO, Cynegeticon 269-271: Quin et promissi spatiosa per aequora campi/ cursibus acquirunt commoto sanguine uires/ paulatimque auidos comites post terga relinquunt. - "Lançados à corrida por vastas planícies -/ o sangue agitado -, ganham força e aos poucos/ deixam para trás ávidos companheiros”. [trad. B. F. S. Maciel] 
Passando a uma observação mais detida do que se dá quando Virgílio e Grattius Faliscus se põem a focalizar os equinos em suas respectivas obras, podemos dizer que, entre v. 72-122 de Geórgicas III, aparecem tópicos em estreita relação com as características desejáveis em um bom cavalo: então, sua ascendência deve ser examinada com critério pelo criador (v. 72); os potros de escol são notados, inclusive, por sua coragem em enfrentar perigos, como um rio ou uma ponte desconhecidos (v. 77-78); a melhor cor, para essa espécie, corresponde à dos baios (v. 82); a pior, ao branco e ao cinza escuro (v. 82-83); a espinha dos potros de qualidade, por sua vez, "estende-se dos dois lados pelos lombos, e a pata escava a terra e ressoa forte com o casco duro" (v. 87-88). ${ }^{19}$

Depois de enfatizar brevemente a inutilidade dos esforços reprodutivos para animais doentes ou idosos (v. 95-100), Virgílio prossegue recomendando:

Então, os ardores e a idade considerarás em primeiro lugar: depois, as outras habilidades, a prole dos pais, qual dor a cada vencido, que glória para a palma. Acaso não vês, quando os carros se apoderaram do campo em veloz disputa e eles correm desenfreados do cárcere, quando a esperança dos jovens se exaltou e um medo pulsante abala os corações que palpitam? Instam com o chicote trançado e soltam as rédeas inclinando-se, voa com força o eixo fervente; ora abaixados, ora erguidos, no alto parecem ser arrastados pelo ar vazio e levantar-se aos ventos; sem demora nem descanso, mas uma nuvem de areia fulva se eleva, molham-se com a espuma e o resfolegar dos que os seguem: tamanho é o amor aos louvores e para tamanho cuidado a vitória. ${ }^{20}$

O fecho dessa seção temática das Geórgicas identifica-se com a evocação, pelo poeta, de antecedentes míticos - a "invenção" da atrelagem dos cavalos a carros por Erictônio e a da montaria pelos lápitas de Peletrônio (v. 113-117) ${ }^{21}$ - de certos usos ainda destinados aos

${ }^{19}$ VIRGÍLIO, Geórgicas III, 87-88: At duplex agitur per lumbos spina, cauatquel tellurem et solido grauiter sonat ungula cornu. [trad. nossa]

20 VIRGÍliO, Geórgicas III, 100-112: (...) Ergo animos aeuomque notabis/ praecipue; hinc alias artis prolemque parentum/ et quis cuique dolor uicto, quae gloria palmae./ Nonne uides, cum praecipiti certamine campum/ corripuere ruontque effusi carcere currus,/ cum spes arrectae iunenum exsultantiaque haurit/ corda pauor pulsans? Illi instant uerbere torto/ et proni dant lora; uolat ui feruidus axis;/ iamque humiles iamque elati sublime uidentur/ aera per nacuom ferri atque adsurgere in auras; / nec mora nec requies; at fuluae nimbus harenae/ tollitur; umescunt spumis flatuque sequentum:/ tantus amor laudum, tantae est uictoria curae! [trad. nossa]

${ }^{21}$ Em Geórgicas III, 89-94, o magister didático, cedendo ao esperado recurso, em uma obra com as vinculações genéricas desta, à mitologia, já relacionara o potro valoroso ao lendário Cílaro, um cavalo domado por Pólux; aos equinos de Marte, aos do carro de Aquiles e a Saturno, um dia metamorfoseado nessa espécie para fugir rapidamente da esposa, que ele traía com Filira (mãe do centauro Quíron). Por outro lado, Erictônio era um 
equinos, para os quais se necessita de espécimes “jovens", "ardentes" e "rápidos na corrida", em que pese à utilidade de animais com outras características para outros tipos de tarefa.

Entre v. 157-178, o teor da preceituação didática de Virgílio se volta para indicar as medidas necessárias na criação dos jovens cavalos, sobretudo, para aqueles destinados aos combates, às corridas nas margens do rio Alfeu, em Pisa, e a "impelir carros velozes no bosque de Júpiter" - et Iouis in luco currus agitare uolantis, v. 181 (trad. nossa). Essas medidas incluem, a saber, habituar os potros às imagens e sons bélicos (como os das trombetas - v. 183), afastá-los das mães e colocar-lhes mordaças sobre as faces (v. 187-189), ensinar-lhes a trotar (v. 191-192) ou a correr (v. 193-195), fazê-los esforçar-se em direção às "metas e enormes espaços das planícies da Élida" - hic uel ad Elei metas et maxima campi/ sudabit v. 202-203 (trad. nossa) -, dar o alimento da "ferrã"22 aos já amansados etc.

Quando nos voltamos para a abordagem da correspondente espécie equina no poema didático de Grattius, o que se vê é, como na primeira seção tratada das Geórgicas - v. 72-122 -, a grande preocupação do poeta em indicar quais tipos de cavalos são melhores para o emprego humano em caçadas. Com efeito, como ressalta já em v. 498-500, "nem toda raça tem ousadia para minhas técnicas: há o defeito do espírito, enganam a outros os fracos corpos, por vezes não ajuda uma coragem destacada". ${ }^{23}$ Desses inícios do trecho considerado de Grattius até v. 535, notamos que o autor, à diferença de Virgílio, concentra-se em aludir a muitas raças de animais ou lugares do mundo, de alguma forma, famosos pelos equinos que produzem: assim, ele menciona em sequência os cavalos da Tessália (v. 501-502); os de Micenas (v. 502-503); os de Siene (= Assuã do Egito); os do país do Partos (v. 507-509); os cavalos ibéricos dos "calecos" (v. 514); os de Nasamônia/Numídia, no norte africano (v. 517 518); os dos bisaltos, na antiga região da Trácia (v. 523-530); os caônios/do Epiro (v. 530531); os dos montes Ceráunios, localizados pelo poeta na Macedônia (v. 532); os de Cirra, lugar situado perto da localidade oracular de Delfos (v. 533-535).

Por fim, ao término da parte ainda conservada de sua única obra conhecida, Grattius pronuncia-se:

antigo rei lendário de Atenas e os lápitas, vinculados aos centauros, eram habitantes da cidade de Peletrônio, na Tessália.

${ }^{22}$ Designa-se por este nome "1. centeio ou cevada colhida antes de espigar, para alimentar o gado; ferranha, ferrejo 2. p. ext. qualquer planta ou erva, cortada à foice e utilizada como forragem verde" (HOUAISS; VILLAR, 2009, p. 887).

${ }^{23}$ GRATTIUS, Cynegeticon, 498-500: (...) non omne genus meas audet in artes./ Est uitium ex animo, sunt quos imbellia fallant/ corpora, praeueniens quondam est incommoda uirtus. [trad. nossa] 
Melhor aliada do caçador é a coloração: são ótimas as pernas negras e escolham os baios... e aqueles cujos dorsos imitam cinzas apagadas. Ó, quanto se destacam as éguas itálicas - foi a vontade dos deuses - e nós nos avantajamos às terras em qualquer prática; e que incansável juventude abrilhanta nossos campos! $!^{24}$

Uma impressão sobre os modos de um e outro autor abordarem o assunto técnico da tipologia equina diz respeito a que Virgílio, como apontamos antes, envereda-se, às vezes, por um caminho de erudição mitológica, não tanto geográfica, como seu correlato de tempos posteriores. Com isso, claramente - embora o mesmo não valha para toda a extensão do Cynegeticon, no qual também se encontram poucas digressões de teor imaginativo $-^{25}$, a dicção de Grattius, em v. 497-535, adquire tons mais "realistas" do que aqueles encontráveis, por exemplo, em Geórgicas III, 89-94 e III, 113-117, com suas ideias alusivas a tantas personagens lendárias e até, dissemos, à história da metamorfose do deus Saturno em cavalo.

Outro aspecto bastante perceptível, quando Virgílio e Grattius tratam em suas obras do aspecto, propriamente, físico a servir de guia para a escolha dos cavalos, é que o autor das Geórgicas não se limitou a oferecer uma gama de traços mais vasta para descrevê-lo entre v. $79-83^{26}$ e v. $86-88^{27}$, e, ainda, fê-lo de forma algo detalhada ${ }^{28}$, nas mesmas passagens: assim,

${ }^{24}$ GRATTIUS, Cynegeticon 536-541: Venanti melius pugnat color: optima nigr $\langle a\rangle$ / 〈cru>ra illi badiosque leg $\langle a>n t$ et.../ <et quo>rum fessas imitantur terga fauillas./ $<O$ quan>tum Italiae (sic di uoluere) parentes/ <praestant> et terras omni praecepimus usu/ <nostraque quam pernix> collustrat prata <iuuentus>! [trad. nossa]

${ }^{25}$ Lembramos que, entre v. 213-252, Grattius esboça uma narrativa vinculada a Hágnon, o qual reputa o primeiro a manejar a raça canina dos metagontes; ora, a figura humana aludida, provavelmente, corresponde a uma personagem lendária, ou mesmo mítica (VERDIÈRE, 1964, p. 294): “On ignore à quelle source grecque Grattius a puisé le nom de ce chasseur. Vlitius croyait qu'il s'agissait d'Hagnias, fils de Tiphys, cité par Apollodore (I, 105). Wensdorf proposait avec prudence de lire Boeotius Haemon en se fondant sur Propert., 2, 8, 21: ... non Antigonae tumulo Boeotius Haemon; mais cet Haemon n'est pas chasseur et son père n'est pas Astylos". Ainda, entre v. 427-464, Grattius compôs um excurso que não deixa de recorrer à presença de um ente sobrenatural, ou até mítico, pois se trata, nesse contexto, de apresentar certa gruta siciliana dedicada ao deus Vulcano, à qual os pastores poderiam levar seus animais doentes, intentando solicitar as graças curadoras de semelhante divindade.

26 VIRGÍLIO, Geórgicas III, 79-83: (...) Illi ardua ceruix/ argutumque caput, breuis aluus obesaque terga,/ luxuriatque toris animosum pectus. Honesti/ spadices glaucique; color deterrimus albis/ et giluo. (...) - "Tem a nuca alta e a cabeça afilada, o ventre pequeno, o dorso gordo, o peito intrépido abunda em músculos. Bons os baios e de olhos verdes, a pior cor têm os brancos e o cinza-escuro". [trad. nossa]

${ }^{27}$ VIRGÍlLIO, Geórgicas III, 86-88: Densa iuba et dextro iactata recumbit in armo;/ at duplex agitur per lumbos spina, cauatquel tellurem et solido grauiter sonat ungula cornu. - "A crina é densa e pende lançada na espádua direita; mas a espinha se estende dos dois lados pelos lombos e a pata escava a terra e ressoa forte com o casco duro". [trad. nossa]

${ }^{28}$ Em alguns dos textos técnicos romanos utilizados por Virgílio como fonte dos saberes rústicos contidos nas Geórgicas, porém, há que observar um grau muito maior de detalhamento e método descritivo no tocante aos corpos dos animais rústicos (TREVIZAM, 2011, p. 87-88): “A passagem acima [VARRÃO, De re rustica II, IX, 3-5], com efeito, trata de oferecer os traços físicos desejáveis nos cães que se adquirem para empregos variados nos fundi rustici - defesa da propriedade e dos bens do senhor, companhia, guarda dos rebanhos... -, de um modo, tanto quanto viável, exaustivo. Assim, nota-se, o escritor percorre os animais de um estremo a outro (do 
abundam adjetivos do tipo de ardua (ceruix, v. 79), argutum (caput, v. 80), breuis (aluuos, v. 80), obesa (terga, v. 80), animosum (pectus, v. 81), honesti (um subentendido equi, ou pulli, v. 81), spadices e glauci (o mesmo subentendido equi, ou pulli, v. 82), deterrimus (color, v. 82), densa (iuba, v. 86), duplex (spina, v. 87) e solido (cornu, v. 88) ${ }^{29}$ para qualificar, nesses trechos contíguos, traços aplicáveis a atributos dos equinos ou a eles em sua inteireza.

Em contrapartida, a própria exiguidade do trecho de Grattius em mais próxima correspondência temática com tais partes do livro III das Geórgicas não permitiu que o autor do Cynegeticon desenvolvesse tanto o aspecto compositivo associável à caracterização corpórea dos cavalos, pois, conforme se nota pelo pequeno excerto acima citado em tradução (v. 536-541), ele se limita a dizer que as "pernas" dos melhores animais dessa espécie deveriam ser "negras", enquanto os equinos, de preferência, "baios", ou com dorsos que semelham "cinzas apagadas". Não devemos, porém, dado o estado fragmentário da obra de Grattius, para nós modernos, com isso inferir que a falta de detalhamento descritivo dos corpos de quaisquer animais focalizados em sua obra seja um dado inquestionável, já que, por exemplo, a seção destinada a apresentar-nos os traços dos cães de caça, no Cynegeticon, destaca-se por um grau de elaboração não desprezível, no mesmo quesito:

Sejam altas as faces, sejam peludas as orelhas junto à testa, grande a boca e, pelos focinhos avantajados, respirem torvelinhos de fogo; que ventres contraídos rodeiem suas entranhas; seja curta a cauda, longo o flanco, o pelo repartido no pescoço, nem penteado em demasia, nem intolerante ao frio; e ainda, dos membros, erga-se um peito que respire amplamente e tolere grandes esforços. Foge do que, com sola espaçosa, espalha seus rastros: é fraco para o ofício. Eu gostaria de pernas rijas, com secos músculos, e patas sólidas para tal lida. ${ }^{30}$

focinho à cauda, vale dizer), sem negligenciar a passagem por zonas intermediárias como o colo, as pernas, as patas, as unhas e o tronco. Além disso, há menção à preferência pelo pelame claro e a especificidade anatômica feminina dos úberes. Por outro lado, a zona anatômica da face surge especialmente bem trabalhada por Varrão: como que pausado em câmera lenta sobre a 'documentação' desta parte específica dos cães, ele logra, assim, apresentar-lhe as características ideais dos olhos, das narinas, dos lábios, do 'queixo' e das presas. Tais esforços representativos, de natureza, anacronismos à parte, quase 'fotográfica' evidentemente se enquadram no projeto geral do autor de oferecer ao público eficazes diretrizes ordenadoras do maior número possível de afazeres rústicos".

${ }^{29}$ As traduções de tais expressões são as seguintes: "nuca alta"; "cabeça afilada"; "ventre pequeno"; "dorso gordo"; "peito intrépido"; "bons" (cavalos/potros); "baios" e "de olhos verdes" (cavalos/potros); "a pior" (cor); "crina densa"; "espinha dúplice"; "casco duro".

30 GRATTIUS, Cynegeticon 269-278: Sint celsi uultus, sint hirtae frontibus aures,/ os magnum et pabulis agitatos naribus ignes/ spirent, adstricti succingant ilia uentres,/ cauda breuis longumque latus discretaque collo/ caesaries neu pexa nimis neu frigoris illa/ impatiens; ualidis tum surgat pectus ab armis,/ quod magnos capiat motus magnisque supersit./ Effuge qui lata pandit uestigia planta:/ mollis in officio. Siccis ego dura lacertis/ crura uelim et solidos haec in certamina calces. [trad. nossa] 
Como derradeiro ponto de comentário nesse subitem do artigo, desejamos frisar que, antes do trecho citado logo acima, Grattius também falara sobre raças de cachorros/seus locais de proveniência (v. 154-262), mantendo-se assim no Cynegeticon, sob o ponto de vista da dispositio, um padrão de fazer seguir-se a apresentação estrita das características físicas dos animais a esse aspecto de sua caracterização, mesmo quando o poeta trata, sequencialmente, dos cavalos. Continuando um pouco nossos exercícios especulativos sobre o que poderia terse encontrado na sequência dessa obra, quanto à abordagem da espécie equina, é difícil, ainda, não supor que um assunto como os cuidados de saúde de tais animais não fosse estar presente no texto, depois de v. 541.

\section{A abordagem destinada a uma doença de pele/scabies em Virgílio - Geórgicas III, 440- 456 - e em Grattius Faliscus - Cynegeticon 408-429}

Cremos de utilidade, antes de realizar qualquer aproximação mais detida entre os dois trechos de Virgílio e Grattius mencionados no subtítulo acima, dizer que o assunto das moléstias a vitimarem os animais postos sob a guarda do homem (ou não) tem importância tanto em Geórgicas III quanto em Cynegeticon. Começando por justificar essa afirmação no âmbito das próprias Geórgicas, tem-se por vezes reconhecido que Amor e a Pestis constituem, justapondo-se em tal parte do poema didático virgiliano, duas significativas forças de ameaça a uma ordem mantida a alto custo pelo agricola, agente maior dos embates rústicos ao longo do poema inteiro (WILKINSON, 1997, p. 96 e 99-100).

Então, apesar de poder-se pensar que o $A m o r^{31}$ fosse antes identificar-se com um lado construtivo da vida nos fundi rustici, pois, sem haver a reprodução, não seria tão fácil manter ou aumentar as cabeças de posse de um pecuarista ${ }^{32}$, o contato mais detido com o livro III das Geórgicas revela que o sexo tratado com descuido tende, aqui, a extrapolar os limites da

\footnotetext{
${ }^{31}$ Este, no contexto em jogo, sobretudo identificado com os instintos sexuais dos seres viventes, cf. Wilkinson (1997, p. 96): “Once again, man and beast are not distinguished: amor omnibus idem. In their times of sexual excitement all animals grow wilder than ever: in furias ignesque ruunt".

${ }^{32}$ Sempre havia, contudo, como atestado no segundo livro do De re rustica de Varrão de Reate - séc. I a.C. - a possibilidade da compra de grupos de animais por um senhor fundiário qualquer: II.V.7. Qui gregem armentorum emere uult, obseruare debet primum, ut sint eae pecudes aetate potius ad fructos ferendos integrae quam iam expartae. - "Quem deseja comprar um rebanho de bois deve primeiro observar que sejam esses animais, pela idade, antes bons para gerar cria do que já estéreis”. [trad. nossa]
}

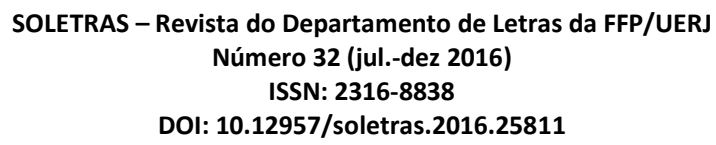


segurança, vindo a resultar na morte daqueles diretamente envolvidos com a volúpia ${ }^{33}$, ou até dos indivíduos expostos a ela de forma indireta ${ }^{34}$.

Por outro lado, ao mencionarmos a Pestis, tal como abordada nas linhas dessa obra de Virgílio, remetemo-nos logo ao relato dos supostos eventos passados na província romana do Noricum, segundo o poeta os apresenta entre III, 474-566. Na verdade, nesse longuíssimo excurso narrativo, são-nos contados acontecimentos em nexo com uma misteriosa - e, ao que tudo indica, irreal e literária ${ }^{35}$ doença que, começando por afetar animais domésticos como os bovinos, cães e outros, passa por contágio a atingir seres silvestres e mesmo o ser humano. O caráter completamente generalizado dessa moléstia, como dissemos, ainda acrescido pelo horror das descrições de seus sintomas ${ }^{36}$, contribui para completar o quadro de turbulento pesadelo também construído, em Geórgicas III, através de evocações das consequências negativas do Amor.

Como se começa a notar pela própria numeração do trecho "recortado" para nossos comentários sobre o mal da scabies (“sarna”) das ovelhas - v. 440-456 -, ele corresponde a uma espécie de porta de entrada, no livro III das Geórgicas, não apenas para o tópico didático das patologias e, consequentemente, dos preceitos de ordem veterinária, mas ainda para toda uma seção bastante mórbida do poema, na qual a gravidade da(s) doença(s) prossegue seguindo o curso de um crescendo fulminante. Isso se dá porque a passagem do livro "geórgico" em pauta relacionada mais de perto com o mal da scabies e sua sequência imediata se fazem apresentando tratamentos, ou soluções para essa e outra(s) moléstia(s), de maneira

\footnotetext{
${ }^{33}$ TREVIZAM, 2012, p. 90: "Em v. 259, em espécie de ilustração deste princípio-mestre da natureza [a rendição ao Amor], o poeta evoca sutilmente a lenda da paixão entre Leandro e Hero, essa uma sacerdotisa de Afrodite separada dele pelo estreito do Helesponto: ocorre que, a cada noite, o moço se entregava a nado às ondas do mar na ânsia de desfrutar das carícias da amante, tendo o mesmo ocorrido até na ocasião em que, estando as águas muito agitadas por conta de uma horrenda tempestade, não conseguiu resistir ao impulso e, ainda assim, aventurou-se nelas... para morrer afogado".

${ }^{34}$ Cf. supra nota 14.

35 WEST, 2007, p. 79 [pronunciando-se sobre um detalhe sintomatológico de Geórgicas III, 485 (o qual quer vincular a uma imitação da Peste humana em Lucrécio, De rerum natura VI, 1190-1191, bem como VI, 1210)]: "All of these details are clinically credible, but not, as we argued, what Virgil made of them, that the bones should gradually dissolve into the fluid. Now, however, the Virgilian idea of dissolving bones becomes explicable. It is a bold and general picture inspired by the loss of foot and hand in Lucretius. It is as though Virgil is supposing that the loss of the extremities means that their bones are dissolved in noxious fluid".

${ }^{36}$ VIRGÍLIO, Geórgicas III, 511-514: Mox erat hoc ipsum exitio, furiisque refecti/ ardebant ipsique suos iam morte sub aegra/ (di meliora piis erroremque hostibus illum!)/ discissos nudis laniabant dentibus artus. "Logo, porém, isso mesmo era o que os destruía, inflamavam-se em fúria reanimados e eles mesmos, já em presença da morte aflitiva (deem os deuses coisas melhores aos bons e aos inimigos aquele delírio!), laceravam só com os dentes seus membros rasgados". [trad. nossa]
} 
mais e mais drástica, como adiante veremos; além disso, quando se passa efetivamente à Peste do Noricum, não há mais perspectiva alguma de curar ou tratar com eficácia dos doentes. ${ }^{37}$

No próprio Cynegeticon de Grattius, a supracitada importância dos temas veterinários em relação com doenças e/ou tratamentos encontra respaldo, além do óbvio interesse do assunto no contexto de um poema didático no qual se pressupõe a posse de animais de auxílio venatório pelo caçador - cães e cavalos, os quais podem adoecer -, no fato de que seu autor se dedica a desenvolvê-lo ao longo da obra por extensão considerável de versos, e com algum detalhamento.

Então, primeiro convém lembrar que, entre v. 344-479, vemo-nos diretamente confrontados, na obra em questão, com assuntos relativos às moléstias dos cachorros, suas causas e tratamentos, sendo possível dividir tal tópico técnico do poema em vários subitens: depois da introdução (v. 344-351), na qual Grattius menciona, de forma vaga e figurada, as ameaças da morte - "paira acima o Fado e o Orco, avidíssimo, o mundo inteiro/ devora, ressoa em torno com negras asas" ${ }^{38}$, segue-se uma seção dedicada a descrever as feridas dos cães (v. 352-365), com suas causas e possíveis soluções (v. 366-382); outra seção (v. 383407), em específico, voltada à abordagem da raiva canina, com seus remédios - "sal/ puro esparge e unta a ferida com pouco azeite" 39 ; outra em que se tematiza a sarna, tópico principal de nossa exposição comparativa nesta parte do artigo (v. 408-426); outra que se identifica com apresentar certa gruta siciliana de Vulcano, deus curador de animais (v. 427-464) e outra (pequena) seção destinada ao comentário sucinto sobre diferentes doenças (v. 477-479), como a tosse, a letargia senil e a gota.

Ainda, temos entre v. 480-496 um trecho de recomendação religiosa aos caçadores, a fim de que sacrifiquem e roguem o auxílio de Diana, deusa patrona de seu métier e, em específico, dos cães:

Por isso construímos santuários de encruzilhada nas altas florestas, colocamos fachos pontudos junto ao sagrado e silvestre recinto de Diana e os cães se recobrem com o adorno de costume; e, no meio do recinto da floresta, pelas flores se depuseram as próprias armas, sem

\footnotetext{
37 VIRGÍLIO, Geórgicas III, 548-550: Praeterea iam nec mutari pabula refert/ quaesitaeque nocent artes; cessere magistri,/ Phillyrides Chiron Amythaoniusque Melampus. - "Além disso, já não adianta que se mudem os alimentos e as artes procuradas prejudicam; desistiram os mestres, Quíron Filírides e Melampo Amitaônio". [trad. nossa]

38 GRATTIUS, Cynegeticon 347-348: Stat Fatum supra totumque auidissimus Orcus/ pascitur et nigris orbem circumsonat alis. [trad. nossa]

${ }^{39}$ GRATTIUS, Cynegeticon 394-395: (...) purum/ sparge salem et tenui permulce uulnus oliuo. [trad. nossa]
} 
uso nos ritos e na paz festiva. Então o cântaro e bolos fumegantes em verde andor precedem, com o bode de chifres a brotar da tenra fronte e com frutos ainda pendentes dos ramos, segundo o hábito do rito purificador, em que a juventude inteira se purifica para a deusa e sacrifica a ela pelo ano. Então, obtidas suas graças, generosa responde aonde pedes seu auxílio; quer vencer os bosques, quer escapar dos flagelos e ameaças dos fados seja tua maior preocupação, a Virgem é tua grande garantia e tutela. ${ }^{40}$

Dessa maneira, como se fala, em v. 495, de "escapar dos flagelos e ameaças dos fados" ${ }^{41}$ e essa última expressão parece ter sido utilizada, já em v. 347, ao modo de uma alusão também aos males que podem advir das doenças aos cachorros, não nos parece descabido ver ainda nesse trecho associável a Diana uma passagem em elos temáticos com o grande tópico didático das doenças de tal espécie, como se aborda com óbvia explicitude e foco entre v. 344-479, segundo vimos.

Passando à própria abordagem comparativa do mal da scabies (“sarna”) em Virgílio e Grattius, inicialmente devemos observar que, à diferença do tópico tratado no subitem anterior desta exposição - cavalos -, um assunto como as moléstias passíveis de atingirem manadas/rebanhos (ou matilhas) se caracteriza como algo de todo justificável em uma e outra obra aqui sob análise, pois, na verdade, doença, decadência e, num extremo, morte não costumam escolher os alvos sobre os quais se abatem ${ }^{42}$. $\mathrm{O}$ exame um pouco mais detido dos trechos que o veiculam em Geórgicas III e em Cynegeticon, por outro lado, revela a participação de importantes diferenças entre um e outro contexto.

Assim, em Virgílio, ocorre muito claramente a divisão do assunto da scabies - "sarna" - em duas partes, uma primeira vinculada a expor as causas desse mal que incide sobre ovelhas (v. 440-444) e outra a oferecer alternativas de tratamento, ou minoração da mesma doença (v. 445-456). Dessa forma, as causas apontadas por Virgílio vinculam-se às más consequências advindas do contato contínuo do corpo dos espécimes com a "chuva fria"

40 GRATTIUS, Cynegeticon 483-496: Idcirco aeriis molimur compita lucis/ spicatasque faces sacrum ad nemorale Dianae/ sistimus et solito catuli uelantur honore,/ ipsaque per flores medio in discrimine luci/ strauere arma sacris et pace uacantia festa./ Tum cadus et uiridi fumantia liba feretro/ praeueniunt teneraque extrudens cornua frontel haedus et ad ramos etiamnum haerentia poma,/ lustralis de more sacri, quo tota iuuentus/ lustraturque deae proque anno redit honorem./ Ergo impetrato respondet multa fauore/ ad partes, qua poscis opem; seu uincere siluas/ seu tibi fatorum labes exire minasquel cura prior, tua magna fides tutelaque Virgo. [trad. nossa]

${ }^{41}$ GRATTIUS, Cynegeticon 495: fatorum labes exire minasque. [trad. nossa]

${ }^{42}$ Como exemplificação literária desse tipo de pensamento generalizante sobre a decadência de todos os seres viventes, cf. Geórgicas III, 66-68: Optima quaeque dies miseris mortalibus aeui/ prima fugit; subeunt morbi tristisque senectus/ et labor, et durae rapit inclementia mortis. - "Cada um dos melhores dias da vida é o primeiro a esquivar-se aos infelizes mortais; insinuam-se as doenças, a triste velhice e o sofrimento, e a inclemência da morte dura arrebata". [trad. nossa] 
(frigidus imber, v. 441) e "o inverno rigoroso, com o branco gelo" (horrida cano/ bruma gelu, v. 442-443).

Por sua vez, os principais tratamentos indicados pelo poeta das Geórgicas são submergir os rebanhos em "cursos de água doce" (v. 445-446), tocar "o corpo tosado com a amurca" - sendo esse último produto um resíduo líquido da fabricação do azeite de oliveira, de muitos usos na economia agrária antiga (v. 448) ${ }^{43}$, misturar "espumas de prata e enxofre vivo, pez do Ida ${ }^{44}$ e ceras viscosas, cebolas-albarrãs ${ }^{45}$, heléboros fortes e o negro betume" (v. 449-451 ${ }^{46}$, para a obtenção de um emplastro, e, sobretudo, "abrir a ferro a parte superior de uma ferida: o mal se alimenta e vive oculto enquanto o pastor se recusa a aplicar mãos curativas às feridas, ou espera pedindo aos deuses que tudo melhore" (v. 453-456). ${ }^{47}$

Grattius Faliscus, que omite em sua preceituação didática qualquer palavra sobre a profilaxia da sarna dos $c \tilde{a} e s^{48}$, aproxima-se de Virgílio ao recomendar o uso de uma mescla de betume tratado com vinho oloroso, pez de Hipona e o "unto da desprezada amurca" (v. 415417); além disso, por solicitar a lavagem das vítimas da dermatose em pauta, com o que, espera-se, o mal abrandará - ast ira coercita morbi/ laxatusque rigor, "então, foi reprimida a fúria da doença/ e o rigor desfeito" (v. 418-419). Tais medidas, contudo, não significam que o tratador de cães, como descrito em Cynegeticon, esteja livre de outros cuidados, pois deverá ainda afastar os animais sob sua guarda das chuvas e dos frios do Cauro (v. 420); mas, quando "o calor paira sobre vales nus, antes os leve, longe do vento, aos raios do sol brilhante, para que exsudem todo o mal e, por outro lado, o tratamento feito penetre pelos poros ocultos"; 49

\footnotetext{
${ }^{43}$ No De agri cultura de Catão, o Censor, obra identificada com o mais antigo "espécime" conhecido de um texto em prosa publicado em latim - séc. II a.C. -, os capítulos XCI-CIII, menos CII, tratam de muitos usos rústicos destinados a esse subproduto de manufatura camponesa. Cf. como exemplo cap. XCVII: Amurca decocta axem unguito et lora et calciamenta et coria; omnia meliora facies. - "Besunta com amurca reduzida o eixo, as correias, os calçados e os couros: vais torná-los todos melhores". [trad. nossa]

${ }^{44} \mathrm{O}$ Ida era um monte das imediações de Troia, cujos pinheiros produziam uma resina pegajosa de aplicações medicinais.

45 Cebolas-albarrãs: referente a uma erva mediterrânea da família das hiacintáceas, que apresenta bulbo empregado para fins médicos. O glossário de nomes de plantas de Jacques André (1985, p. 229), por sua vez, identifica esse vegetal como algo correspondente à espécie chamada Urginea maritima.

${ }^{46}$ VIRGÍlIO, Geórgicas III, 449-451: Et spumas miscent argenti uiuaque sulpural Idaeasque pices et pinguis unguine ceras/ scillamque elleborosque grauis nigrumque bitumen. [trad. nossa]

${ }^{47}$ VIRGÍLIO, Geórgicas III, 453-456: (...) rescindere summum/ ulceris os: alitur uitium uiuitque tegendo,/ dum medicas adhibere manus ad uolnera pastor/ abnegat et meliora deos sedet omnia poscens. [trad. nossa]

${ }^{48}$ Não consideramos profiláticos, de prevenção, os ditos de v. 419-420 [(...) quae te ne cura timentem/ differat, et pluuias et Cauri frigora uitent. - "Não te disperse, temeroso, esse/ cuidado, e evitem as chuvas e os frios do Cauro". (trad. nossa)], pois são posteriores ao tratamento dos cães doentes, muito embora, em autores como Virgílio (Geórgicas III, 441-443) e Catão (De agri cultura V), umidade e/ou frio, sendo condições supostamente favoráveis ao surgimento da sarna das ovelhas, devam ser a todo custo evitados.

${ }^{49}$ GRATTIUS, Cynegeticon 421-424: Duc magis, ut nudis incumbunt uallibus aestus, / a uento clarique faces ad solis, ut omne/ exsudent uitium subeatque latentibus ultro/ quae facta est medicina uadis. (...) [trad. nossa]
} 
enfim, "Péan (Apolo) protege e tem ajudado, propício às técnicas, aquele que mergulha seus cães nas correntes da praia espumosa" (v. 424-426)..$^{50}$

Sobre esse mesmo aspecto dos cuidados aos animais vitimados pela sarna, sejam eles ovelhas ou cachorros, a depender do poema, um detalhe comentado por Verdière (1964, p. 380) ajuda a divisar um pouco melhor a natureza das relações entre os preceitos veterinários de Virgílio e Grattius. Assim, como nota o crítico francófono, os autores antigos de "agronomia" nem sempre recomendam os banhos como parte do tratamento da sarna dos animais, embora uma preceituação orientada nesse sentido esteja presente, por exemplo, além de no poema de Grattius, nas obras de Catão - De agri cultura (séc. II a.C.) -, Virgílio Geórgicas (séc. I a.C.) - e Columela - De re rustica (séc. I d.C.). Contudo, dentre os autores citados, somente Columela e, em tempos prévios a Grattius, Catão encontram "eco" mais preciso no Cynegeticon de que falamos, pois recomendam que a unção dos animais doentes deve preceder o gesto curativo de serem eles banhados:

Para que as ovelhas não fiquem sarnentas: conserva a "amurca" $e$ purifica-a bem. Mistura-a entre si em partes iguais com a água de cozimento do tremoço e a borra de um bom vinho. Em seguida, quando tosares, besunta-as inteiramente e deixa que ressudem por dois ou três dias. Em seguida, lava-as no mar; se não tiveres água do mar, faze água salgada e lava com ela. Se fizeres assim, não terão sarna, terão mais e melhor lã e os carrapatos não incomodarão. Usa o mesmo para todos os quadrúpedes, se tiverem sarna. ${ }^{51}$

Por isso os pastores submergem todo o rebanho em cursos d'águadoce, o carneiro de velos úmidos é mergulhado num lago e, solto, desliza no rio corrente; ou tocam o corpo tosado com a "amurca" acerba, misturam espumas de prata e enxofre vivo, pez do Ida e ceras viscosas, cebolas-albarrãs, heléboros fortes e o negro betume. ${ }^{52}$

50 GRATTIUS, Cynegeticon 424-426: (...) Nec non tamen illum/ spumosi catulos mergentem litoris aestu/ respicit et facilis Paean adiuuit in artes. [trad. nossa]

${ }^{51}$ CATÃO, De agri cultura XCVI: Oues ne scabrae fiant. Amurcam condito, puram bene facito, aquam in qua lupinus deferuerit et faecem de uino bono, inter se omnia conmisceto pariter. Postea cum detonderis, unguito totas, sinito biduum aut triduum consudent. Deinde lauito in mari; si aquam marinam non habebis, facito aquam salsam, ea lauito. Si haec sic feceris, neque scabrae fient et lanae plus et meliorem habebunt, et ricini non erunt molesti. Eodem in omnes quadripedes utito, si scabrae erunt. [trad. nossa]

52 VIRGÍlLIO, Geórgicas III, 445-451: Dulcibus idcirco fluuiis pecus omne magistri/ perfundunt udisque aries in gurgite uillis/ mersatur missusque secundo defluit amni,/ aut tonsum tristi contingunt corpus amurca/ et spumas miscent argenti uiuaque sulpura/ Idaeasque pices et pinguis unguine ceras/ scillamque elleborosque grauis nigrumque bitumen. [trad. nossa] 
E assim, também betumes tratados com vinho oloroso, pez de Hipona e o unto da desprezada "amurca" o fogo misturou e abarca em um só todo. Depois, lavam os doentes: então, foi reprimida a fúria da doença, e o rigor desfeito (...). ${ }^{53}$

Nos trechos acima, na verdade, podemos ver que em Catão e Grattius, apenas, os autores antepuseram o emprego de substâncias curativas sobre a pele dos animais doentes sendo que, no primeiro, esses correspondiam a ovelhas, não a cachorros! - à sua lavagem. Apesar de não haver, em Grattius, imediatas especificações nesse último quesito ${ }^{54}$ - note-se que Catão recomenda de chofre o banho curativo nas águas marinhas, naturais ou artificialmente feitas -, ele também se identifica com os conselhos veterinários do Censor, além do ponto mencionado no início deste parágrafo, por incluir em sua receita de emplastro, em adição à amurca, o próprio vinho, esse presente na obra do autor do De agri cultura sob a forma da "borra".

Em contrapartida, quando consideramos a passagem transcrita de Geórgicas III, em que pese à coincidência ao menos parcial entre os ingredientes nela empregados sobre as lesões cutâneas das ovelhas e aqueles do "receituário" de Cynegeticon 415-419 (amurcalamurca; pez do Ida/pez de Hipona), conforme vimos, tudo ocorre como se o magister didático não tivesse desejado a retirada de seu emplastro do corpo dos animais sob tratamento. Por sinal, entre os três trechos de recomendação veterinária em pauta, é claramente perceptível que a "receita" virgiliana, a conter nada menos que oito ingredientes, corresponde àquela mais elaborada: assim, em Catão e Grattius, sempre prevalece a maior sobriedade de recorrer a três substâncias básicas apenas. Essa riqueza de recursos, ou "falta de economia" do preceituador das Geórgicas, talvez possa ser levada em conta como fator de justificativa para sua recomendação de evitar que tantos ingredientes - sendo, no mínimo, o pez ideu um produto importado -, ao permanecerem por algum tempo sobre a pele já limpa pela água, simplesmente se dispersem em rios ou lagos.

Sem dúvida, dados como esses expostos aqui, no tocante à forma de tratamento da sarna recomendada por cada escritor antigo em discussão - Catão, Virgílio e Grattius -,

53 GRATTIUS, Cynegeticon 415-419: Tunc et odorato medicata bitumina uino/ Hipponiasque pices neclectaeque unguen amurcael miscuit et summam complectitur ignis in unam./ Inde lauant aegros: ast ira coercita morbi/ laxatusque rigor. (...) [trad. nossa]

${ }^{54}$ Entre v. 424-426, supracitados, Grattius parece especificar melhor, entretanto, o tipo de água (marinha) mais recomendável para a submersão terapêutica dos cães vitimados pela scabies. Note-se, então, que também ao recomendar o banho em água salgada, não doce, como no livro III das Geórgicas, esse poeta se aproxima mais de Catão do que de Virgílio, como preceituador de veterinária. 
contribuíram para que o supracitado Verdière entendesse não apenas ser o De agri cultura catoniano correspondente à base do autor do Cynegeticon para fazer o banho seguir-se à unção dos animais doentes, mas ainda caber a esse pequeno manual agrícola (cap. XCVI), não tanto às Geórgicas, a condição de constituir a fonte principal de Grattius para a tessitura do todo dos versos 415-419 de seu poema (VERDIÈRE, 1964, p. 377).

Grattius também parece ter "invertido" a ordem dos conselhos veterinários de Virgílio porque se pôs, logo no início de suas recomendações sobre a sarna, o duro preceito relativo a ter-se de matar os animais severamente doentes (v. 408-412). Em Virgílio, no entanto, versos de teor parecido apenas se encontram em III, 464-469, quando o magister didático das Geórgicas recomenda livrar-se sem demora de uma ovelha portadora de estranhos sintomas e, por sinal, alheios aos incômodos da moléstia de pele aludida! -, a fim de coibir perdas mais graves, advindas do contágio sobre o rebanho inteiro:

Vendo alguma ao longe, ou que se aproxima com muita frequência da sombra suave, ou que come um tanto sem vontade as pontas da relva e segue por último, ou que se prostra no meio do campo ao pastar e, tarde da noite, retira-se sozinha, logo lhe reprime o mal a ferro, antes de o terrível contágio insinuar-se pelo rebanho desprevenido. ${ }^{55}$

Mas, se a sarna persegue um corpo lesado com feio comichão, a via de dilatada morte é a pior: ao primeiro sintoma, é amargo o remédio, mas deve-se pagar resgate da ruína com uma só existência, a primeira atingida pelo mal inclemente, para duros contágios não arrastarem o bando. ${ }^{56}$

Como se anunciou antes, ao introduzirmos a questão geral das moléstias no livro III das Geórgicas, não interessaria a Virgílio “quebrar o suspense”, apresentando logo no começo da seção veterinária de seu poema um "tratamento", ou melhor, medida tão extrema quanto esse sacrifício purgador do rebanho: assim, entre v. 440-473 primeiro lhe pareceu melhor recomendar, contra a sarna, um banho (v. 445-447) ou uma unção medicamentosa (v. 448-

${ }^{55}$ VIRGÍLIO, Geórgicas III, 464-469: Quam procul aut molli succedere saepius umbrae/ uideris aut summas carpentem ignauius herbas/ extremamque sequi aut medio procumbere campo/ pascentem et serae solam decedere nocti,/ continuo culpam ferro compesce, priusquam/ dira per incautum serpant contagia uolgus. [trad. nossa]

${ }^{56}$ GRATTIUS, Cynegeticon 408-412: At si deformi lacerum dulcedine corpus/ persequitur scabies, longi uia pessima leti:/ in primo accessu tristis medicina, sed una/ pernicies redimenda anima, quae prima sequaci/ sparsa malo est, ne dira trahant contagia uulgus. [trad. nossa] 
451); depois, o corte da parte de cima das chagas com certo instrumento afiado (v. 452-456); depois, ao que tudo indica, já com referência a outro mal, a abertura de uma veia sob a pata de animais enfraquecidos (v. 459-463); enfim, o sacrifício como acima transcrito, o qual preludia os horrores do contágio sobre todos os seres e a morte inevitável, após longo sofrimento e sucessivas pioras, no próprio excurso da Peste do Noricum (v. 474-566).

Ora, em Grattius, talvez devido ao próprio caráter marcadamente técnico do texto, não temos a criação do mesmo efeito expressivo em escalada de gravidade, mas apenas a direta proposição de que, caso o cachorro vitimado pelo mal cutâneo em jogo já não possa ser cuidado, traz mais vantagem ao dono a morte de um, não a perda da matilha inteira. Desse modo, a aparente imitação desse detalhe mórbido de Virgílio não priva o autor do Cynegeticon de adaptá-lo ao contexto de um poema, por vezes, visto como "secamente" informativo (GAILLARD; MARTIN, 1990, p. 209-210), o que neste caso se dá não só sob o aspecto do novo ordenamento sequencial obtido, mas inclui, segundo acabamos de ver, um encaixe mais "utilitarista" da ideia do sacrifício entre v. 408-426.

\section{Conclusão}

Como buscamos discutir nos dois subitens anteriores, as semelhanças eventualmente constatáveis entre os poemas didáticos identificados com as Geórgicas de Virgílio, em sua terceira parte, e com o Cynegeticon de Grattius Faliscus (pertença a um mesmo gênero literário, abordagem de assuntos que se vinculam ao trato de animais como cavalos e cães, de temas veterinários e sobre as raças/tipos em nexo com essas criações etc.) não podem fazernos esquecer de que cada poeta considerado tratou, ao seu modo, dos "mesmos" tópicos nos versos de seus respectivos poemas.

Assim, acima destacamos que Virgílio pronuncia-se bem mais sobre os cães, quantitativamente falando, do que Grattius; que a inserção dos equinos no dia a dia de trabalho dos fundi rustici romanos, na Antiguidade, soa mais ou menos artificial, ao contrário do que poderia fazer pensar o grande destaque dado à espécie em Geórgicas III; que o mesmo não se dá com sua inserção em um poema venatório como o Cynegeticon de Grattius, fato atestado pela própria abordagem reiterada da equinocultura em várias obras de caça antigas; que Virgílio parece detalhar, mais que Grattius, o aspecto das descrições físicas dos equinos (Geórgicas III, 79-83/86-88) - embora não seja, nesse quesito, comparável ao rigor expositivo de um Varrão de Reate, em De re rustica II, IX, 3-5; que o autor do Cynegeticon, por outro 
lado, alude com certa erudição geográfica a muitas zonas do mundo reconhecidas pelos equinos que nelas se originam (v. 498-535), enquanto Virgílio, ao demonstrar sua erudição livresca sobre esses animais, preferiu, com menor dose de "realismo" explicativo, vinculá-los a lendas e personagens da mitologia (Geórgicas III, 89-94/113-117).

Sobre, ainda, o aspecto das (parciais) diferenças encontráveis entre as duas obras analisadas, quando consideramos, em específico, o assunto patológico da sarna, deve-se fazer a ressalva de que esse tema não mais corresponde a algo "alheio" ao plano da interação humana com a natureza em nenhuma delas. Contudo, outras semelhanças à parte nesse quesito, entre Virgílio e Grattius - emprego medicinal da amurca e de pez, recomendação de banhos, eventual recorrência, ao menos no entorno dos versos a veicularem conteúdos atinentes à moléstia de pele aludida (Geórgicas III, 440-473/Cynegeticon 408-429), ao conselho relativo a sacrificar espécimes doentes etc. -, os dois poetas se diferenciam porque a sarna é dos cães, não das ovelhas, em Cynegeticon; porque Grattius, como Catão do De agri cultura (cap. XCVI), preferiu a lavagem do emplastro medicamentoso a ser empregado sobre a pele dos animais (v. 415-419), algo nunca encontrado em Virgílio (v. 445-451); porque o sacrifício precede todo o restante e não se liga a uma cadeia de fatalidade crescente, no poema de caça em questão etc.

Então, o cotejo a que procedemos acima, em escala reduzida, permite-nos compreender que há mais de um tipo de poesia didática possível, oscilando-se, por exemplo, entre as concessões imaginativas/mitológicas de Virgílio e o "ancoramento" na realidade de certos aspectos da diç̧ão de Grattius, ou entre a "secura" expositiva desse último e a recorrência do autor das Geórgicas a determinados efeitos expressivos de dispositio dos assuntos rústicos. Tais dados, ainda, encontram confirmação nas palavras daqueles, como Dalzell (1996, p. 123-124) e FLORIO (1997, p. 49), que rechaçam qualquer visão das Geórgicas ao modo de um texto, antes de mais nada, destinado a instruir agricultores para suas ações quotidianas de trabalho rústico. ${ }^{57}$

\footnotetext{
${ }^{57}$ Em contrapartida, sobre a postura didática mais "comprometida" de Grattius, cf. Toohey (2004, p. 241): "Instruction, rather than play, conditions Grattius' text. The utilitarian dominates poetic texture. Whimsy and wordplay are excluded (there is none of that humor or misdirection that calls into doubt the applicability of the material being broadcast)".
} 


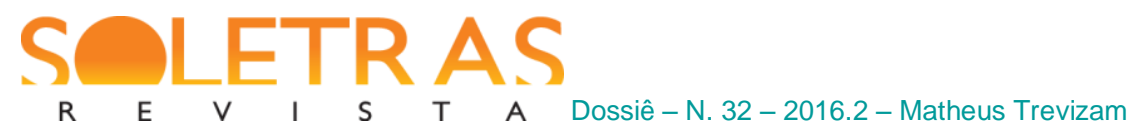

\section{Referências}

AMAT, J. Les animaux familiers dans la Rome antique. Paris: Les Belles Lettres, 2002.

ANDRÉ, J. Les noms des plantes dans la Rome antique. Paris: Les Belles Lettres, 1985.

AYMARD, J. À propos de Grattius. Revue de Philologie, de Littérature et d'Histoire anciennes, Paris, vol. 12, p. 325-329, 1938.

CATO; VARRO. On agriculture. Trad. W. D. Hooper, revised by H. B. Ash. Cambridge. Mass./London: Harvard University Press, 2006.

DALZELL, A. The criticism of didactic poetry: essays on Lucretius, Virgil and Ovid. Toronto/Buffalo/London: The University of Toronto Press, 1996.

FLORIO, R. Poesía didáctica y oratoria en Roma. Bahía Blanca: Editorial de la Universidad Nacional del Sur, 1997.

GAILLARD, J.; MARTIN, R. Les genres littéraires à Rome. Paris: Nathan/Scodel, 1990.

GRIMAL, P. Dictionnaire de la mythologie grecque et romaine. Paris: Presses Universitaires de France, 1963.

HOUAISS, A.; VILLAR, M. S. Dicionário Houaiss da Língua Portuguesa. $1^{\text {a }}$. edição. Rio de Janeiro: Objetiva, 2009.

KRONENBERG, L. Allegories of farming from Greece and Rome. Cambridge/New York: Cambridge University Press, 2009.

LILLY, M. L. The Georgic: a contribution to the study of the vergilian type of didactic poetry. Baltimore: J. H. Furst Company, 1917.

MACIEL, B. F. S. O campo encantado nas Bucólicas e nos Cynegetica de Nemesiano. Monografia inédita de conclusão de curso (bacharelado em latim). Belo Horizonte: Faculdade de Letras da UFMG, 2014 [98 p.].

MOYA, F. Poesia "menor". Siglos I y II d.C. In: CODOÑER, C. (org.). Historia de la literatura latina. Madrid: Cátedra, 2007, p. 449-492.

PUBLILIUS SYRUS et alii. Minor Latin poets: vol. I. Cambridge, Mass./London: Harvard University Press, 1982.

ROBERT, J.-N. La vie à la campagne dans l'Antiquité romaine. Paris: Les Belles Lettres, 1985.

RODRÍGUEZ, J. A. C. Introducción [a los Cynegetica de Gratio]. In: . (org.). Poesía latina pastoril de caza y pesca. Madrid: Gredos, 1984, p. 9-15. 
TOOHEY, P. Epic lessons: an introduction to ancient didactic poetry. London/New York: Routledge, 1996.

Passing time: hunting, poetry and leisure. In: . Melancholy, love and time:

boundaries of the self in ancient literature. Ann Arbor: Michigan Press, 2004, p. 222-260.

TREVIZAM, M. Distintos tratamentos lexicais e textuais dos plantéis pelo Virgílio de "Geórgicas” III e por Varrão ("De re rustica” II). Phaos, Campinas, vol. 12, p. 5-27, 2012.

Imagens da ruralidade no "Cato Maior", de Cícero, e no "De re rustica", de Varrão reatino: questões preliminares. Nuntius Antiquus, Belo Horizonte, vol. 7, n. 2, p. 81-100, jul.dez. 2011.

Poesia didática: Virgílio, Ovídio e Lucrécio. Campinas: Unicamp, 2014.

VARRÃO. Das coisas do campo. Trad., introdução e notas de Matheus Trevizam. Campinas: Unicamp, 2014.

VERDIÈRE, R. Poetae bucolici Cynegeticique minores: première partie - Gratti Cynegeticon Libri I quae supersunt (volume II, commentaire par Raoul Verdière). Wetteren: Universa, 1964.

VIRGILE. Géorgiques. Texte trad. par E. de Saint-Denis. Paris: Les Belles Lettres, 1998.

VOLK, K. The poetics of Latin didactic: Lucretius, Vergil, Ovid, Manilius. Oxford: Oxford University Press, 2002.

WEST, D. Two plagues: Virgil, "Georgics" 3.478-566 and Lucretius 6.1090-1286. In: WEST, D.; WOODMAN, T. (org.). Creative imitation and Latin Literature. Cambridge: Cambridge University Press, 2007, p. 71-88.

WILKINSON, L. P. The "Georgics" of Virgil: a critical survey. Norman: Oklahoma University Press, 1997.

\title{
Parallels between Cynegeticon and Virgil's Georgics book III
}

\begin{abstract}
This article intends to compare the teaching techniques presented in specific parts of the poems of Virgil (Georgics, book III) and Grattius Faliscus (Cynegeticon), having as reference for the first poem the v. III, 72-122/179-208, which is comparable with the v. 497 541 of the second poem, both dealing with horse caring; likewise, the v. III, 440-456, of Virgil's work is comparable with the v. 408-429 of Grattius', both dealing with sheep and dog scabies, respectively. The intention is to refine an understanding of how such texts move
\end{abstract}


closer or away from each other, due to their inner poetic characteristics. The theoretical benchmark used here points out to the idea of literary genders as it is to be seeing in a recurring and continuous way in Classical Studies and, particularly, to the notion of ancient poetry teaching, which, sharing other researchers' impressions, can be divided into subtypes (TOOHEY, 1996/2004). The results obtained through the comparison of some Virgil's and Grattius' related passages lead this work to the conclusion that in Georgics III prevails a type of textual structure, guided towards aesthetic joy and public imagination, while, in Cynegeticon, the author is often too informative about hunting matters.

Keywords: Literary genre. Ancient didactic poetry. Comparison.

Recebido em: 27 de setembro de 2016.

Aprovado em: 01 de dezembro de 2016. 